\title{
The Hunger
}

Joseph L Graves Jr. ${ }^{1,2}$

Keywords: Neuroscience; Cognition; Evolution

\section{Book Review}

The Ravenous Brain: How the New Science of Consciousness Explains our Insatiable Search for Meaning, by Daniel Bor. New York: Basic Books, 2012. Pp. xviii + 326. H/b \$27.99, ISBN-13: 978-0465020478, ISBN-10: 046502047X.

Evolutionary scientists do not doubt that the human brain is the seat of our consciousness. Unfortunately evolutionary reasoning has not dominated the history of scholarly investigation into the subject. Daniel Bor's book is an attempt to explain why we cannot gain much useful insight into the subject of consciousness absent evolutionary principles. His main thesis is that the most plausible view of consciousness is that it is produced by an organism's brain (of which the human brain seems to be the most complex of its kind in the known universe.) He argues that the human brain is a form of biological computer, and that consciousness arises from information processing, since data processing is the overriding purpose of our inner neuronal world.

In some ways this book is a deeply personal enterprise for the author. In the introduction he admits that his motivation to study brain neuroscience resulted from his father's debilitating stroke. Despite that what follows in this book is a primarily objective examination of both the history of and current state of brain science and consciousness. He begins by taking apart the classic philosophical mind body duality of Descartes and others (Chapter One: Conceptual Conundrums of Consciousness). His use of the famous case of Phineas Gage in the service of this analysis is powerful. He ends this chapter taking on some of the $20^{\text {th }}$ century philosophical objections against the mind as a biological machine (The Chinese Room argument.) In the next chapter (A Brief History of the Brain) he presents the core of his evolutionary argument for the brain as biological computer. The selection pressure for organs such as the brain results from the need to process useful information (and from the evolutionary perspective, this means information that increases the survivorship and reproduction of individuals.) Interestingly enough, he did not review arguments for sexual selection and brain function here. There is also one claim made about animal learning, concerning the risk of death stemming from some ideas that I disagree with. Specifically natural selection would only favor learning as a strategy only if it leads to differential reproductive success; this could include cases of where survivorship is even decreased so long as the net reproductive output of organisms that learn is greater than those who do not. Despite this shortcoming, the chapter is for the most part filled with good examples and makes an effective argument for his main thesis of the brain as biological computer.

Chapters 3-7 are packed with mechanistic details of how the brain produces consciousness. This is important reading, as it debunks many common misconceptions concerning the relationship of brain structure, activity, and function. From the viewpoint of evolutionary biology chapter 6: Being Bird-Brained is Not an Insult, is particularly valuable. In this chapter, Bor provides examples demonstrating that consciousness exists in other animals. Most readers will not be surprised by evidence of consciousness in Bonobos, but may be a little more skeptical that it exists in birds (such as crows). Finally, chapter seven (Living on the Fragile Edge of Awareness), presents powerful evidence concerning the brain as the root of our consciousness. This chapter examines how profound brain damage alters consciousness. Again examples are given which address many common misconceptions concerning brain function, awareness, and consciousness. The last chapter posits that many mental disorders may indeed be alterations of consciousness. Again, there is a personal influence on this analysis, as the author admits that his wife suffers from what has been diagnosed as bipolar disorder. He proposes that bipolar depression may be "not enough consciousness to go around" and bipolar mania as "too much consciousness for her brain to cope with". He also applies this thesis to explain features of 
autism, unhealthy sleep patterns, and working memory disease such as ADHD and schizophrenia.

In summary, The Ravenous Brain presents a powerful analysis of how evolution has shaped our brains and their resulting consciousness. It explains why our brains are hungry for information and how this influences our consciousness. It brings together a well-reasoned examination of evolutionary theory and basic neuro- and brain science. It provides the reader with important ideas concerning how a better grasp of the union of evolution and neuroscience may be a boon to medical and psychiatric interventions into mental illness. This book should be read as part of the training of physicians, neuroscientists, psychiatrists, and psychologists.

\section{Competing interests}

The author declares that he has no competing interests.

Received: 7 October 2014 Accepted: 8 October 2014

Published online: 20 February 2015

\section{Submit your manuscript to a SpringerOpen ${ }^{\odot}$ journal and benefit from:}

- Convenient online submission

- Rigorous peer review

- Immediate publication on acceptance

- Open access: articles freely available online

- High visibility within the field

- Retaining the copyright to your article

Submit your next manuscript at $\gg$ springeropen.com 